\title{
Potassium isotope composition of mantle peridotite
}

\author{
DMITRI A. $\operatorname{IONOV}^{1}$ AND KUN WANG (王昆) ${ }^{2}$ \\ ${ }^{1}$ Geosciences Montpellier, Université de Montpellier and \\ CNRS UMR 5243, 34095 Montpellier, France \\ (dmitri.ionov@umontpellier.fr) \\ ${ }^{2}$ Department of Earth and Planetary Sciences and McDonnell \\ Center for the Space Sciences, Washington University in \\ St. Louis, MO 63130, USA (wangkun@wustl.edu)
}

Potassium is highly incompatible in peridotites, the most common upper mantle rocks. Melt extraction from the Bulk Silicate Earth early in the Earth's history concentrated much of the $\mathrm{K}$ in the proto-crust and thus dramatically reduced its concentration in the remaining depleted asthenospheric mantle. Subsequent recurring melting of the asthenosphere left behind solid residues, even more depleted in $\mathrm{K}$, which eventually accumulated to form the continental lithospheric mantle (CLM). Parts of the initially melt-depleted, hence Kpoor, CLM were later metasomatized, i.e. transformed by additions of (and/or reaction with) different melts and fluids. These metasomatic media are usually enriched in incompatible elements, including $\mathrm{K}$, originating from multiple sources such as the asthenosphere, mantle plumes and recycled surface materials. The sum of these processes over billions of years of the Earth's history has produced a CLM with highly heterogeneous $\mathrm{K}$ distribution, which is poorly constrained.

Recent advances in high-precision analysis of $\mathrm{K}$ isotopes suggest that $\mathrm{K}$ isotopes are not fractionated by hightemperature igneous processes such as partial melting and fractional crystallization. In contrast, the alteration and dehydration of subducted crustal materials would generate large $\mathrm{K}$ isotope fractionation between the residual slab and the released fluid. Therefore, $\mathrm{K}$ isotopes can be a robust tool to study $\mathrm{K}$ cycling between the crust and mantle, as well as a sensitive tracer for different sources of metasomatic melts and fluids.

Here, for the first time, we report high-precision $\mathrm{K}$ isotope compositions of a large number of xenolith peridotites. These samples include: (a) variably melt-depleted nonmetasomatized peridotites; (b) whole-rock samples affected by multiple types and degrees of metasomatism; and (c) most common K-bearing metasomatic phases (amphibole, phlogopite, and quenched melt glass) separated from metasomatized peridotites. The data suggest that $\mathrm{K}$ isotopes are strongly fractionated in arc mantle as well as in veined and other heterogeneous mantle rocks possibly due to kinetic fractionation during fluid-rock interaction. 